\title{
QUANDO A ÉTICA SE TORNA MORAL: CONSIDERAÇÕES SOBRE O SISTEMA CEP NO BRASIL
}

\author{
JULIANA LOPES DE MACEDO ${ }^{1}$
}

\begin{abstract}
RESUMO
0 presente artigo tem como objetivo refletir sobre o caráter contratualista e legalista dos Comitês de Ética e Pesquisa, a partir da análise de três elementos com os quais me deparei ao longo de minha trajetória enquanto pesquisadora: 1) a falta de homogeneidade nas avaliações éticas; 2) a falta de acesso e a objeção de consciência presentes em alguns Comitês e; 3 ) a centralidade do Termo de Consentimento Livre e Esclarecido para determinar o caráter ético de uma pesquisa. Defendo a ideia de que o sistema CEP/Conep está ancorado em uma perspectiva moral regida pela legalidade e pelo contratualismo, que resume a ética em pesquisa a um conjunto de procedimentos morais que não soluciona as desigualdades de poder entre pesquisadores e pesquisados.
\end{abstract}

\section{PALABRAS-CHAVE \\ Comitês de Ética em Pesquisa; Contratualismo; Moral}

\section{WHEN ETHICS BECOME MORAL: CONSIDERATIONSABOUT THE CEP SYSTEM IN BRAZIL}

\begin{abstract}
The objective of this article is to reflect on the contractualist and legalistic nature of the Ethics and Research Committees, based on the analysis of three elements that I came across during my career as a researcher: 1 ) the lack of homogeneity in ethical evaluations; 2) lack of access and conscientious objection present in some Committees; 3 ) the centrality of the Term of Free and Informed Consent to determine the ethical character of a research. I defend the idea that the CEP / Conep system is anchored in a moral perspective governed by legality and contractualism, which summarizes research ethics to a set of moral procedures that do not solve the inequalities of power between researchers and researchers.
\end{abstract}

\section{KEY-WORDS}

Ethics Committees in Research; Contractualism; Moral

\section{LORSQUE L'ETHIQUE DEVIENT MORAL : CONSIDERATIONS SUR LE SYSTEME DE CEP AU BRESIL}

\section{RÉSUMÉ}

Cet article vise à réfléchir sur le contractualiste et le caractère légaliste du Comité d'éthique de la recherche, de l'analyse à trois éléments avec lesquels je suis tombé sur toute ma carrière en tant que chercheur: 1) le manque d'homogénéité dans les évaluations éthiques; 2 ) le manque d'accès et de l'objection de conscience et présente dans certains comités; 3 ) le caractère central du consentement éclairé et éclairé pour déterminer le caractère éthique d'une recherche. Je soutiens l'idée que le système CEP / CONEP est ancré dans une perspective morale

${ }^{1}$ Professora Adjunta da Universidade Federal do Pampa. 
régie par la loi et par contractualisme, qui résume l'éthique de la recherche à un ensemble de procédures morales ne résout pas les inégalités de pouvoir entre les chercheurs et les recherches.

\author{
MOTS-CLÉS \\ Comités d'éthique de la recherche; contractualisme; moral \\ CUANDO LA ÉTICA SE CONVIERTE EM MORAL: CONSIDERACIONES SOBRE EL SISTEMA CEP EN \\ BRASIL
}

\title{
RESUMEN
}

El presente artículo tiene como objetivo reflexionar sobre el carácter contractualista y legalista de los Comités de Ética e Investigación, a partir del análisis de tres elementos con los que me encontré a lo largo de mi trayectoria como investigadora: 1) la falta de homogeneidad en las evaluaciones éticas; 2) la falta de acceso y la objeción de conciencia presentes en algunos Comités; 3) la centralidad del Término de Consentimiento Libre y Esclarecido para determinar el carácter ético de una investigación. La idea de que el sistema CEP / Conep está anclado en una perspectiva moral regida por la legalidad y el contractualismo, que resume la ética en investigación a un conjunto de procedimientos morales que no soluciona las desigualdades de poder entre investigadores e investigadores.

\section{PALABRAS-CLAVE}

Comités de Ética en Investigación; Contratualismo; Moral 
Historicamente, a ciência e o conhecimento são dimensões sociais bastante valorizadas e, talvez por isso, por muito tempo se pensou (e, às vezes, ainda se pensa) que a ciência e o conhecimento, por si só, se justificariam. A discussão sobre ética, pesquisa e ciência irá ganhar forma apenas após a segunda guerra mundial, quando fica evidente para o mundo ocidental os crimes e atrocidades cometidos, "em nome da ciência", pelos médicos do regime nazista. A partir do julgamento realizado nos Estados Unidos dos crimes dos médicos nazistas, a corte que julgou os casos decidiu que, para que essas atrocidades não mais se repetissem, era necessário criar diretrizes para a atuação dos pesquisadores médicos. É, então, formulado o Código de Nuremberg em 1949.

No entanto, o Código de Nuremberg estava muito associado ao julgamento dos crimes nazistas e ao próprio nazismo. Dessa forma, ele não foi alvo de discussões, reflexões e operacionalização por parte dos pesquisadores que não conseguiam se reconhecer como semelhantes aos médicos nazistas e, portanto, não implicados na discussão sobre ética em pesquisa. Foi apenas na década de 1960 que as preocupações sobre ética em pesquisa ganharam espaço no campo da saúde. Nesse sentido, três eventos foram definidores para essa mudança de percepção: 1) a revelação do projeto governamental Tuskegee Study, realizado na cidade Tuskegee, Estados Unidos, que tinha como objetivo acompanhar o desenvolvimento da sífilis no paciente, sem que os pacientes soubessem que tinha sífilis e não administrando tratamento, mesmo após este ser descoberto; 2) o caso da Talidomida, que foi testada amplamente em mulheres, muitas em idade reprodutiva, sem o consentimento delas e sem conhecimentos sobre os riscos e 3) a publicação de Henry Beecher sobre pesquisas não éticas (DINIZ; GUILHEM, 2007). Desses três eventos, sem dúvida, a pesquisa de Beecher foi a que encontrou o terreno mais fértil para a discussão sobre ética em pesquisa. Se os casos de Tuskegge e da Talidomida pareciam "eventos pontuais" e limitados (assim como os médicos nazistas), a pesquisa de Beecher demonstrou que a falta de ética na pesquisa não era limitada em número de casos e se expandia para todo o Ocidente. Beecher é um médico anestesista que colecionava artigos de pesquisa orientadas por princípios pouco éticos e escreveu um artigo revelando cinquenta casos de pesquisas que possuíam uma noção de ética bastante deturpada por ele identificados. Ao analisar as referências dessas pesquisas, o autor encontrou muitas outras pesquisas com os mesmos problemas, como se fosse uma progressão geométrica, ou seja, não se tratava de "apenas" cinquenta casos (BEECHER, 1966). A publicação de Beecher teve um grande impacto na comunidade médica, alertando sobre a necessidade de estabelecer princípios éticos para a realização de pesquisas. Nesse sentido, inspirada pelo Código de Nuremberg, a Associação Médica Mundial (AMM), formulou em 1964 a Declaração de Helsinki que tem sido orientadora para a prática de pesquisas médicas no mundo. 
O Código de Nuremberg e a Declaração de Helsink são documentos que versam sobre o estabelecimento de normas éticas para pesquisas clínicas. No Brasil, a regulamentação sobre ética em pesquisa fica a cargo da Comissão Nacional de Ética em Pesquisa (CONEP), órgão vinculado ao Conselho Nacional de Saúde. Essa estrutura organizacional já dá o contorno da discussão ética empreendida no Brasil: a sua vinculação à área biomédica, da mesma forma como ocorreu no contexto norte americano. No Brasil, a primeira regulamentação sobre ética em pesquisa também se ocupa de pesquisas clínicas e biomédicas. Nos últimos anos, o debate sobre ética em antropologia tem ganhado força e o evento que motiva essa discussão está bastante associado à regulamentação brasileira sobre ética em pesquisa. Isso não significa dizer, porém, que não havia a preocupação com a ética no campo antropológico. A própria constituição da disciplina enquanto o estudo da alteridade e do método etnográfico pressupõe uma dimensão ética de respeito pelo grupo pesquisado.

No que diz respeito ao sistema CEP/Conep, antropólogos brasileiros afirmavam que a regulamentação está voltada para a área biomédica que assume o sujeito de pesquisa quase como se fosse uma "cobaia", no sentido de que será realizada uma intervenção (a administração de um novo medicamento ou o teste de um novo procedimento). Dessa forma, há uma intervenção direta no corpo do sujeito de pesquisa da biomedicina, o que Cardoso de Oliveira (2004) define como pesquisa em seres humanos. No entanto, na pesquisa antropológica o processo de pesquisa é bastante diferenciado, não se busca uma intervenção, mas sim, uma interlocução com os sujeitos de pesquisa, caracterizando-se assim, como pesquisa com seres humanos. Seguindo a tendência norte-americana, recentemente, as ciências sociais foram incluídas no rol de pesquisas que necessitam passar por uma avaliação ética e, para isto, uma nova regulamentação - a Resolução 510/2016² - foi publicada para dar conta das especificidades do campo.

Esperava-se que uma regulamentação específica para as ciências sociais e humanas diluiria as tensões entre pesquisadores destas áreas e os Comitês de Ética, por se acreditar que as especificidades epistemológicas das ciências sociais e humanas seriam traduzidas para essa nova Resolução. Contudo, o que se observa é que a Resolução 510/2016 limita-se a aplicar e adaptar a mesma lógica contratualista das Resoluções anteriores. O problema, porém, não reside na Resolução em si, mas sim no próprio sistema CEP/Conep, e tampouco se restringe a um campo do conhecimento.

\footnotetext{
${ }^{2}$ No Brasil, podemos destacar três Resoluções do CONEP que regulamentam a ética na pesquisa envolvendo seres humanos: 1) a Resolução 466/96, primeira regulamentação da ética em pesquisa no Brasil, que possuí um enfoque estritamente biomédico em sua concepção de pesquisa e de ética; a Resolução 196/12, que revoga a anterior, apresentando basicamente os mesmos princípios éticos e a mesma concepção de pesquisa, entretanto, definido com mais precisão a nomenclatura utilizada; 3) a Resolução 510/2016 que versa especificamente sobre as normas éticas de pesquisas das ciências humanas que envolvem seres humanos.
} 
Durante minha trajetória acadêmica e profissional tenho realizado pesquisas em serviços de saúde, principalmente hospitais, portanto, mesmo na época em que a regulamentação sobre ética em pesquisa não havia atingido as ciências sociais, a avaliação ética e aprovação do projeto de pesquisa por um CEP sempre me foi imposta como condição sine qua non para a execução de uma pesquisa. Desde minha primeira experiência em submeter um projeto para avaliação ética de um CEP até este momento, três elementos me chamam atenção em relação ao sistema de avaliação dos CEPs: 1) a falta de homogeneidade nas avaliações éticas realizadas pelos (EPs; 2 ) a falta de acesso e a objeção de consciência de alguns CEPs e; 3 ) a centralidade do TCLE para determinar o caráter ético de uma pesquisa. Desse modo, o presente artigo tem como objetivo refletir sobre o caráter contratualista e legalista dos CEPs com base nesses três elementos com os quais me deparei ao longo de minha trajetória enquanto pesquisadora.

\section{UM PESO, DUAS MEDIDAS: A PLURALIDADE DAS AVALIAÇÕES ÉTICAS}

Em minha primeira experiência de submissão de um projeto para avaliação ética - na época tratava-se de minha pesquisa de mestrado sobre as concepções médicas em relação à morte encefálica (MACEDO, 2008; MACEDO, 2016) -, precisei submetê-lo à três diferentes Comitês: o Comitê da Universidade na qual eu realizava a pós-graduação e aos Comitês dos dois hospitais nos quais a pesquisa seria realizada. Foi com muita surpresa que recebi duas avaliações nas quais nenhum dos apontamentos coincidiam. Ora, se a regulamentação da ética em pesquisa no Brasil segue uma única Resolução (naquele momento existia apenas a Resolução 466/96), não seria de esperar um único resultado para duas avaliações éticas do mesmo projeto?

Um primeiro problema da regulamentação da ética na pesquisa no Brasil é sua clara inspiração na teoria principialista, que estabelece enquanto princípios éticos e universais a beneficência, a não maleficiência, a autonomia e a justiça. No entanto, os críticos da teoria principialista apontam para a impossibilidade de aplicação prática para esta teoria, tendo em vista que não há uma orientação sobre quais destes princípios prevaleceria sobre os demais, e ainda, questionam se de fato estamos diante de uma teoria ou de uma bricolagem malfeita de quatro teorias da filosofia moral, a saber: a beneficência de John Stuar Mill, a não maleficiência da tradição hipocrática, a autonomia de Immanuel Kant e a justiça de John Rawls (DINIZ; GUILHEM, 2007). Desta forma, não existiria uma teoria principialista, tendo em vista que não há uma teoria moral que una os quatro princípios. Na prática isso significa que o principialismo não oferece um guia único para a ação, capaz de estabelecer normas claras, coerentes e justificadas (DINIZ; GUILHEM, 2007). De acordo com Diniz e Guilhem,

"Essa é uma dificuldade comprovada pelas tentativas práticas de instrumentalizar os princípios diante de casos concretos de conflito moral. Ao inexistir uma conexão entre 
eles, cada princípio pressupõe uma soberania em relação aos outros, havendo uma espécie de disputa. Como não há prioridades nem existem procedimentos específicos que solucionem as dúvidas sobre qual valor deve dominar, as soluções dependem de julgamentos particulares sobre a importância de cada princípio" (2007, p. 36).

Na falta de um corpo teórico consistente que justifique as decisões sobre ética na pesquisa, o sistema CEP/Conep acaba por traduzir a ética para uma lógica legalista e jurídica (uma resolução), portanto, baseada na ideia de justiça, o que contribui para essa pluralidade nas avaliações éticas dos projetos de pesquisa:

"Desde Aristóteles, a justiça tem sido entendida como ordem universal, seja mediante a comutação (as ações e reciprocidade e de equilíbrio equitativo), seja mediante a redistribuição (as ações de proporcionalidade e do estabelecimento de méritos). (...) No sentido prático, o justo é o ideal equitativo dos direitos e dos deveres, da precisão e do rigor, da justeza das ações. No sentido subjetivo, o justo é uma atividade moral, e o proceder que não está baseado em uma inclinação (amor, amizade, benevolência, simpatia), nem em uma obrigação para com o outro (virtude). (...) Justiça é uma invenção social que encerra um conceito, mas que admite muitas interpretações de como esse conceito se aplica na prática. Por isso, carece de uma teoria, de um processo lógico que estabeleça o conteúdo e a ordenação dos seus princípios normativos" (THIRY-CHERQUES, 2011, p. 552).

O que se observa no sistema CEP/Conep é que a justificativa para a ação (a ética) está ancorada em resoluções (leis) que buscam estabelecer direitos e deveres equilibrados para sujeitos de pesquisa e pesquisadores com base na ideia de justiça (moral). É importante comentar que a justiça baseia-se na elasticidade das leis e em seu caráter interpretativo, o que torna as decisões parciais e morais. Segundo Dworkin (2010) a posição assumida por aquele que julga estará diretamente vinculada às suas convicções morais, dessa maneira, a moral é tão presente no campo da justiça que acaba sendo parte integrante dele.

Se assumimos, como propõe Dworkin (2010) que a moral é parte constituinte do direito, temos que levar em consideração que nas sociedades complexas observa-se uma pluralidade moral, permitindo que a sociedade interprete uma mesma situação a partir de diferentes pontos de vista. Ao aplicar a lógica da justiça e da legalidade para a ética na pesquisa, permite-se que a pluralidade moral daqueles que avaliam os projetos de pesquisa submetidos aos CEPs seja traduzida para suas decisões. Em certa medida, a garantia desta pluralidade é benéfica para a discussão sobre ética em pesquisa, entretanto, essa pluralidade não se reflete nas regulamentações sobre ética.

\section{CONTROLE MORAL DA ÉTICA NA PESQUISA}

Para corroborar o argumento de que o sistema CEP/Conep é regido mais pela moral do que pela ética, abordo nesta seção as dificuldades em ter acesso a alguns CEPs e as implicações disto. Como referi logo acima, ao realizar minha pesquisa de mestrado, me deparei com a necessidade de submeter meu projeto para três diferentes CEPs, porém, recebi apenas duas avaliações. Isso se deve ao fato de que em um dos hospitais no qual eu 
realizaria minha pesquisa, o acesso ao CEP егa exclusivo para pesquisadores que eram funcionários da instituição. Na tentativa de solucionar o entrave, a sugestão que me foi dada pelo CEP do referido hospital era obter uma autorização extraoficial por parte do responsável do serviço onde a pesquisa seria realizada e a utilização do TCLE registrado no CEP de minha Universidade.

Durante o doutorado - quando pesquisava as concepções de médicos e magistrados sobre aborto de fetos anencéfalos ${ }^{3}$ (MACEDO, 2012; MACEDO, 2015) -, me deparei com a mesma situação em um outro hospital. A sugestão que me foi dada pelo CEP desta instituição, no entanto, foi radicalmente diferente e, do meu ponto de vista, não muito ética: eu deveria procurar algum funcionário do hospital para que ele assinasse o projeto como pesquisador responsável, dessa maneira, o projeto poderia ser submetido ao CEP desta instituição. O problema disto é que os direitos autorais da pesquisa seriam compartilhados por alguém totalmente alheio ao projeto. Como isto poderia ser ético e, ainda por cima, uma recomendação de um CEP? Por mais que o sistema CEP/Conep tenha como pressuposto a pluralidade na composição de seus membros, observa-se muitas vezes o predomínio de profissionais da saúde compondo o CEP, o que pode fazer com que algumas normas que regem o campo da saúde, como o corporativismo, sejam transpostas para os CEPs, interferindo em seu funcionamento. Chama atenção, também, que ao não permitir que pesquisadores externos realizem pesquisas nas dependências destas instituições, parece que as instituições estão considerando que os sujeitos de pesquisas são propriedades institucionais.

Considerando que esta proposição não refletia em nada os pressupostos da ética em pesquisa e que o projeto já havia sido aprovado em dois outros CEPs, decidi negociar minha entrada em campo colocando aos meus futuros informantes desta instituição a impossibilidade de obter a autorização do CEP da instituição. Ao conversar com o chefe do serviço sobre este tema ele afirmou que, se fosse o caso, ele poderia emprestar seu nome como pesquisador responsável do projeto, contudo, não valeria a pena o trabalho de fazer a submissão porque eu jamais seria autorizada por aquele CEP a pesquisar ali aborto de fetos anencéfalos. Vale mencionar que o hospital que sediava este CEP, e prestava atendimento para clientes do SUS, não realiza nenhuma modalidade de aborto, nem mesmo aqueles

\footnotetext{
${ }^{3}$ Até abril de 2012, o aborto de fetos anencéfalos não era reconhecido como um direito das mulheres grávidas desses fetos e, caso a mulher desejasse por fim a sua gravidez, era necessário obter uma autorização judicial. Algumas autorizações eram negadas enquanto outras eram concedidas. Nesse sentido, o objetivo deste trabalho é compreender as concepções médicas e jurídicas sobre aborto de fetos anencéfalos, averiguar as justificativas utilizadas para conceder ou negar as autorizações judiciais e analisar as tensões envolvidas entre o campo jurídico e o campo médico a partir do caso da anencefalia. Foi realizada uma pesquisa de orientação etnográfica na qual foram entrevistados médicos e magistrados diretamente envolvidos nesta questão. Além disso, realizou-se a análise de um conjunto de decisões judiciais sobre aborto de fetos anencéfalos julgados entre 2001 e 2011 pelo Tribunal de Justiça do Rio Grande do Sul.
} 
previstos em lei devido sua vinculação religiosa. E, ao que me parece, o tema do aborto por si só representava um tabu. Porém, os CEPs deveriam ser instituições autônomas para julgar o caráter ético de uma pesquisa, como poderiam, então, não autorizar pesquisas que abordem um determinado tema, mesmo quando a pesquisa não apresente nenhum problema ético? Poderia um CEP se declarar como objetor de consciência?

A objeção de consciência é uma garantia que os profissionais da saúde possuem para não realizar procedimentos que ferem, de alguma maneira, suas convicções morais. Em relação à objeção de consciência institucional, a filósofa Donda (2011) afirma que esse direito pertence apenas aos indivíduos e que uma instituição médica não pode se recusar a realizar um procedimento que tenha amparo legal. A objeção de consciência protege os atores situados no nível da ação, aqueles que colocam "a mão na massa". Desse modo, como não será a instituição hospitalar que realizará o aborto, não cabe a ela ser um objetor de consciência e impedir que seus médicos realizem um aborto legal. Da mesma forma que não seria ético proibir uma pesquisa apenas e tão somente por ela abordar um tema envolto a muitos conflitos morais. Evidentemente que os entraves que encontrei nestas duas instituições não foram criados diretamente pelo sistema CEP/Conep e sim pelos agentes que operacionalizam o sistema. Contudo, essas situações podem indicar problemas na fiscalização e no controle dos CEPs, responsáveis por garantir a ética na pesquisa no Brasil

\section{AFINAL, QUEM É PROTEGIDO PELO TCLE?}

Para mim, que pesquiso entre médicos e magistrados, o TCLE sempre funcionou como um facilitador do diálogo estabelecido entre eu e meus interlocutores, pois, para médicos, o TCLE representa o caráter ético da pesquisa e dessa forma me dá credibilidade entre eles e, entre os magistrados, ele funciona como um contrato, o que é muito próximo da área de atuação jurídica. Para o meu campo de estudo, utilizar o TCLE significa que eu conheço e compartilho dos mesmos acordos e normas da comunidade a qual meus informantes pertencem, o que cria um sentimento de empatia e confiança no meu trabalho como pesquisadora. Se este documento pode gerar constrangimentos para alguns pesquisadores das ciências humanas, para mim ele sempre funcionou como um facilitador do encontro etnográfico.

Рara o sistema CEP/Conep esse tipo de "contrato" nasce pela necessidade de proteger os informantes dando-lhes, através das informações sobre a pesquisa, a autonomia para participar desta. Mas, no meu caso, estamos falando de dois grupos que divergem da lógica pensada para os sujeitos de pesquisa do sistema CEP/Conep, os "pacientes", no meu caso, tratam-se agentes que constituem os chamados campos ups. Durante as entrevistas, a autoridade que Caldeira (1980) e Cardoso de Oliveira (1990) atribuem ao entrevistador 
frente ao entrevistado foi relativizada, ou invertida. Por mais que eu estivesse guiando a conversa, a maior parte dos meus entrevistados não se colocava como informante, mas sim como fontes de pesquisa. Entretanto, pensando nos sujeitos de pesquisa ideais da Conep, os pacientes, é preciso refletir o quanto o modelo proposto para mediar a relação entre pesquisador e pesquisado é, de fato, esclarecido. Esse ponto tem sido alvo de discussão na antropologia, mas também, na própria biomedicina. Em uma pesquisa realizada por Goldim (1999) sobre a compreensão do TCLE por sujeitos de pesquisa, se verificou que são necessários, pelo menos, nove anos de estudo para o que o sujeito tenha uma compreensão adequada do TCLE. Na realidade brasileira, nove anos de estudo representa um percentual pequeno de participantes de pesquisas médicas, principalmente, se considerarmos que as pessoas que estão dispostas a testar novos medicamentos e técnicas pertencem às camadas mais pobres da população. Isso leva a outro ponto fundamental: a pesquisa em biomedicina é realizada, na maioria das vezes, com "pacientes", ou seja, os usuários do serviço de saúde ao qual o pesquisador está vinculado, também, como profissional. Nesse sentido, é questionável a liberdade de negar a participação que o usuário de fato terá, tendo em vista, que pode sempre estar presente a dúvida em relação à qualidade do atendimento se ele não concordar em participar do estudo.

Mesmo com as críticas e as conhecidas limitações do TCLE enquanto garantia da autonomia dos sujeitos pesquisados, a centralidade deste instrumento é evidenciada em todas as Resoluções da Conep, até mesmo naquela que se propõe a "flexibilizar" o uso do TCLE. Antes da formulação da Resolução 510/2016, o TCLE poderia representar um impedimento, ou pelo menos um complicador para pesquisadores que desenvolvem seus estudos com populações ágrafas, analfabetas, ou com pessoas que participam de alguma atividade ilegal, como tráfico de drogas ou aborto. A Resolução 510/2016 minimiza esse inconveniente ao possibilitar outras formas de registros do consentimento do participante da pesquisa, tais como

"... por meio de sua expressão oral, escrita, língua de sinais ou de outras formas que se mostrem adequadas, devendo ser consideradas as características individuais, sociais, econômicas e culturais da pessoa ou grupo de pessoas participante da pesquisa e as abordagens metodológicas aplicadas" (CONEP, 2016, p. 05).

Chama atenção o fato de que se não houver um registro documental para o consentimento é possível comprová-lo através "de testemunha que não componha a equipe de pesquisa e que acompanhou a manifestação do consentimento" (CONEP, 2016, p. 07). A necessidade de documentação ou testemunhas para comprovar que o informante foi informado e consentiu em participar do estudo remete, novamente, à lógica legalista e contratualista da ética na pesquisa, como foi apontado anteriormente.

A teoria do contrato social cunhada por Hobbes (2014) estabelece que as vantagens da vida social só são obtidas se cada parte obedecer às regras estipuladas e se houver 
mecanismos (como sanções penais, por exemplo) que coíbam as partes de quebrar o acordo. Ou seja,

"Esse 'contrato social' é a base da moralidade. De fato, a moralidade pode ser definida como nada mais e nada menos do que o conjunto de regras que pessoas racionais concordariam em obedecer, para o seu benefício mútuo, desde que as outras pessoas também obedeçam." (RACHELS, 2014, p. 21).

John Rawls, que inspira o princípio da justiça para a teoria principialista, argumenta que o "contrato ideal" é um acordo firmado por agentes livres, racionais e iguais baseado nos princípios fundamentais da justiça que seriam o princípio da liberdade e do reequilíbrio das desigualdades. Estes dois princípios são considerados por Rawls como princípios neutros, tendo em vista que seriam bons para todos (THIRY-CHERQUES, 2011), ou seja, "A pedra de toque da teoria da justiça é a retomada da filosofia do contrato social: a ideia de um acordo racional ou razoável, baseado no interesse particular e universal e fruto do consentimento de todos" (THIRY-CHERQUES, 2011, p. 557). Transpondo a teoria contratualista de Rawls para a lógica da ética em pesquisa, especialmente, do TCLE, é possível observar que o princípio da liberdade está representado através da autonomia em decidir participar, ou não, de uma pesquisa. Já o princípio do reequilíbrio das desigualdades é traduzido a partir do fornecimento de informações claras, precisas e completas sobre a pesquisa que se pretende realizar, afim de colocar o participante em uma posição de igualdade a do pesquisador. Como afirma Fonseca (2015), desde o Código de Nuremberg se admite para as regulamentações que tratam da ética na pesquisa, o caráter fundamental do consentimento voluntário para os participantes de uma pesquisa. Dessa maneira, "Esse sujeito não só devia ser legalmente capaz e numa posição de exercer seu livre direito de escolha, também deveria 'ter conhecimento suficiente do assunto para tomar uma decisão'. Mas permaneciam interpretações diversas dessas cláusulas. Como avaliar o 'conhecimento suficiente'?" (FONSECA, 2015, p. 341).

No que concerne às pesquisas biomédicas, parece que o TCLE resolve todas as questões da ética em pesquisa e da relação estabelecida entre sujeitos de pesquisa e pesquisador. Em outras palavras, o uso do TCLE parece garantir, por si só, que toda a negociação no recrutamento dos participantes da pesquisa foi conduzida de forma ética. Tendo em vista que, como foi apontado anteriormente, a ética em pesquisa surge como uma questão na medicina, principalmente, por causa da falta de consentimento das pessoas envolvidas em alguns estudos, o TCLE representa um instrumento importante para a condução das pesquisas biomédicas. No entanto, é preciso lembrar que ele é um instrumento que, para atingir sua meta, precisa de uma postura adequada, ou seja, ética. Muitas vezes, o TCLE é usado como se fosse um contrato que protege, principalmente, o pesquisador de futuras implicações legais (algo como, "mas ele foi avisado e consentiu") e 
garante a possibilidade de publicar os resultados de sua pesquisa em revistas do campo da saúde.

Caldeira (1980) questiona por que alguém se submeteria a participar de uma pesquisa e responder uma série de questões que estarão expondo a sua vida para um desconhecido. Para mim, esta pergunta pode ser respondida por duas vias: 1) a ciência no ocidente possui o estatuto de ser a fonte de conhecimento mais verdadeira e inquestionável que existe; e 2) a associação entre saber científico, produção de verdades e poder é a base da relação entre pesquisador e pesquisado, pois dá ao pesquisador as condições necessárias para executar a sua pesquisa e fornece ao pesquisado a ideia da obrigatoriedade de se submeter à pesquisa (CALDEIRA, 1980). Isto significa que a relação de pesquisa é uma relação de poder. E as posições desiguais ocupadas por participantes de pesquisas e pesquisadores não são solucionadas, simplesmente, com a assinatura de um contrato.

Acredito que um tópico fundamental que tem sido discutido pela antropologia, e ignorado pelo sistema CEP/Conep, é que o consentimento envolve um processo de negociação e interação que não se esgota na assinatura de um documento. Isso significa dizer que o pesquisador precisa assumir uma postura ética que não é obtida através do TCLE, mas ocorre com base nos três princípios éticos explicitados por Cardoso de Oliveira. O primeiro compromisso é com "a verdade e a produção do conhecimento em consonância com os critérios de validade compartilhados na comunidade de pesquisadores" (2010, p. 27). Isso significa afirmar que é vedado ao pesquisador manipular ou apresentar dados falsos de sua pesquisa. O segundo compromisso está voltado para “...o respeito pelos sujeitos de pesquisa, cujas práticas e representações constituem o foco da investigação (daí a ideia da pesquisa com seres humanos e não em seres humanos)" (2010, p. 27). Por fim, o terceiro compromisso proposto por Cardoso de Oliveira é para com a sociedade e a cidadania. A operacionalização desse compromisso ocorre através da "divulgação dos resultados da pesquisa, usualmente por meio de publicações, e eventualmente demanda a intervenção pública do pesquisador, quando esses resultados são distorcidos para beneficiar interesses que ameacem direitos da população pesquisada" (2010, p. 28). Рara o autor, esse compromisso representa uma obrigação moral com o grupo pesquisado, com a finalidade de auxiliar na compreensão da sociedade sobre o problema pesquisado. Além disso, representa um compromisso que o antropólogo assume com o grupo pesquisado que não se encerra após a coleta de dados (CARDOSO DE OLIVEIRA, 2010).

\section{CONSIDERAÇÕES FINAIS}

Ao longo deste artigo, defendi a ideia de que o sistema CEP/Conep está ancorado em uma perspectiva moral regida pela legalidade e pelo contratualismo, que resume a ética 
em pesquisa a um conjunto de procedimentos morais que não soluciona as desigualdades de poder entre pesquisadores e pesquisados. A falta de uma coesão para as avaliações éticas, a centralidade do TCLE e os entraves impostos por alguns CEPs corroboram com a ideia de que o sistema CEP/Conep não garante, por si só, a condução ética das pesquisas realizadas no Brasil, independente da área de conhecimento dos pesquisadores. Além disto, a forma como se trata a ética na pesquisa no Brasil não fornece subsídios para a reflexão e a construção daquilo que seria desejável enquanto uma postura ética do pesquisador. Ou, melhor dizendo, em como se adotar uma postura ética que não se encerra após a coleta de dados e considera as repercussões sociais dos resultados da pesquisa. Essas questões não serão solucionadas com a redação de uma nova resolução. Acredito que o caminho que se deva seguir a partir deste ponto seja, como sugere Fonseca (2015), a busca por formas alternativas ao sistema CEP/Conep, como por exemplo, a discussão europeia que tem buscado formas coletivas e leigas de participação na tomada de decisões sobre os rumos da ciência e do fazer científico.

\section{REFERÊNCIAS}

BEECHER, Henry. Ethics and Clinical Research. The New England Journal of Medicine, v. 274, n. 24, p. 1354-1360, 1966.

CALDEIRA, Teresa Pires. "Uma incursão pelo lado 'não- respeitável' da pesquisa de campo". Caxambu: IV Encontro anual da ANPOCS, 1980, mimeo.

CARDOSO DE OLIVEIRA, Roberto. A antropologia e seus compromissos ou responsabilidades éticas. In: Soraya Fleischer; Patrice Schuch. (0rg.). Ética e regulamentação na pesquisa antropológica. Brasília: UnB \& Letras Livres, 2010. p. 25-38.

CARDOSO DE OLIVEIRA, Roberto. 0 mal-estar da ética na antropologia prática. In: Ceres Victora et al (Orgs.). Antropologia e Ética: o debate atual no Brasil. Niterói: EdUFF, 2004. p. 21-32.

CARDOSO DE OLIVEIRA, Roberto. 0 saber, a ética e a ação social. Revista Internacional de Filosofia da USP, v. XIII, n. 2, p. 07-22, 1990.

CONEP - CONSELHO NACIONAL DE SAÚDE. Resolução 510, 07 de abril de 2016.

DINIZ, Débora; GUILHEM, Dirce. 0 que é bioética. São Paulo: Brasiliense, 2007.

DONDA, Cristina Solange. Los Imperativos de La Conciencia, 2011. Disponível em: http://www.clam.org.br/publique/cgi/cgilua.exe/sys/start.htm?infoid=8377\&sid=103\&tpl=view BR 0125 Acesso em junho de 2017.

DWORKIN, Ronald. A Justiça de Toga. São Paulo: Editora WMF Martins Fontes, 2010. 
FONSECA, Claudia. Situando os Comitês de Ética em Pesquisa: o sistema CEP (Brasil) em perspectiva. Horizontes Antropológicos, v. 21, n. 44, p. 333-369, 2015.

GOLDIM, José Roberto. Consentimento Informado e a adequação de seu uso na pesquisa em seres humanos. Porto Alegre, 1999. (Tese de Doutorado). Programa de Pós-Graduação em Medicina: Clínica Médica da Faculdade de Medicina - Universidade Federal do Rio Grande do Sul.

HOBBES, Thomas. Leviatã ou matéria, forma e poder de um Estado eclesiástico e civil. 2. Ed. São Paulo: Martin Claret, 2014.

MACED0, Juliana Lopes de. A Subversão da Morte: um estudo antropológico sobre as concepções de morte encefálica entre médicos. Porto Alegre, 2008, $173 \mathrm{fls.} \mathrm{(Dissertação} \mathrm{de} \mathrm{Mestrado).} \mathrm{Programa} \mathrm{de}$ Pós-Graduação em Antropologia Social, Universidade Federal do Rio Grande do Sul.

MACED0, Juliana Lopes de. As Regras do Jogo da Morte Encefálica. Revista de Antropologia, v. 59, p. 32-58, 2016.

MACEDO, Juliana Lopes de. Quando a Vida encontra a Morte: as concepções médicas e jurídicas sobre anencefalia e morte encefálica. Porto Alegre, 2012, 255 fls. (Tese de Doutorado). Programa de PósGraduação em Antropologia Social, Universidade Federal do Rio Grande do Sul.

MACED0, Juliana Lopes de. The multiple meanings of 'risk': views on the abortion of non-viable fetuses among Brazilian medical doctors and magistrates. Vibrant (Florianópolis), v. 12, p. 204-230, 2015.

RACHELS, James. Uma breve introdução à filosofia moral. In: RACHELS, James; RACHELS, Stuart (Orgs.). A Coisa Certa a Fazer: leituras básicas sobre filosofia moral. Porto Alegre: AMGH Editora, 2014. p. 13-31.

THIRY-CHERQUES, Hermano Roberto. John Rawls: a economia moral da justiça. Revista Sociedade e Estado, v.23, n.03, p.551-563, 2011. 